\title{
Satellite Ozone Retrieval Under Broken Cloud Conditions: An Error Analysis Based on Monte Carlo Simulations
}

\author{
Alexander A. Kokhanovsky, Bernhard Mayer, Vladimir V. Rozanov, Kathrin Wapler, Lok N. Lamsal, \\ Mark Weber, John P. Burrows, and Ulrich Schumann
}

\begin{abstract}
This paper investigates the influence of horizontally inhomogeneous clouds on the accuracy of total ozone column retrievals from space. The focus here is on retrievals based on backscattered ultraviolet light measurements in Huggins bands in the range of $315-340 \mathrm{~nm}$. It is found that simplifying the description of cloud properties in the ozone-retrieval algorithm studied can produce errors of up to $6 \%$, depending on the error in the assumed cloud parameters. Yet another finding is the fact that independent pixel approximation suffices for ozone-retrieval algorithms. This was found using three-dimensional Monte Carlo radiative transfer calculations in the Huggins bands.
\end{abstract}

Index Terms-Clouds, remote sensing, total ozone column, 3-D radiative transfer.

\section{INTRODUCTION}

$\mathbf{T}$ HE INFLUENCE of clouds on total ozone retrieved from satellite observations is usually studied while assuming horizontally homogeneous plane-parallel clouds [6], [8]-[10], [12], [15]-[17], [23]. In reality, clouds are inhomogeneous at all spatial scales. Therefore, it is important to understand how broken cloud conditions influence ozone retrievals, which are based on several a priori assumptions (e.g., the cloudtop height or the cloud albedo) and approximations (e.g., the independent pixel approximation, IPA). Simple approximations for clouds, such as the IPA, which permit easy retrieval of cloud parameters from spectral data, enable fast cloud corrections to the retrieved ozone columns; however, little is known about the errors encountered in using such simple cloud models to describe the effect of broken clouds on the retrieved ozone. The Monte Carlo technique for radiative transfer enables the solution of the forward problem for arbitrary cloud conditions, using a conceptually simple model of photon paths in an arbitrary inhomogeneous atmosphere plus underlying surface system. Synthetic top-of-atmosphere (TOA) radiances obtained that way can be used in any ozone-retrieval scheme for error analysis and sensitivity studies.

Manuscript received May 6, 2006; revised August 22, 2006. This work was supported by DFG Project BU688/8-2 and Project MA 2548/1-1.

A. A. Kokhanovsky, V. V. Rozanov, M. Weber, and J. P. Burrows are with the Institute of Environmental Physics, University of Bremen, 28334 Bremen, Germany.

B. Mayer, K. Wapler, and U. Schumann are with the Institute of Atmospheric Physics, German Aerospace Center Oberpfaffenhofen, 82234 Wessling, Germany.

L. N. Lamsal was with the Institute of Environmental Physics, University of Bremen, 28334 Bremen, Germany. He is now with the Dalhousie University, Halifax, NS B3H 4R2 Canada.

Digital Object Identifier 10.1109/TGRS.2006.886188
This paper is structured as follows. In Section II, we review the Monte Carlo radiative transfer technique and study the accuracy of the IPA, which is routinely used in ozone total column retrievals from space. Section III is devoted to the study of the relative errors in the ozone retrievals, applying the Weighing Function Differential Optical Absorption Spectroscopy (WF-DOAS) algorithm to artificially generated radiance spectra. Section IV summarizes the results and draws conclusions.

\section{3-D RADIATIVE TRANSFER AND THE IPA}

\section{A. Forward Model}

Modern satellite-based ozone-retrieval techniques are exclusively based on the assumption that 3-D radiative transfer effects can be ignored [1]. This assumption includes that individual satellite ground pixels can be considered independently of each other and that subpixel inhomogeneity can be neglected. While the first assumption is certainly fulfilled for field of views as large as those of the Global Ozone Monitoring Experiment (GOME) and Scanning Imaging Absorption Spectrometer for Atmospheric Chartography (SCIAMACHY) instruments [2], [3], the second one may introduce considerable uncertainties. In case of GOME and SCIAMACHY, subpixel inhomogeneity is considered using the IPA, assuming that the TOA reflectivity $R(\lambda)$ of a ground scene can be calculated as a linear combination of a clear sky $R_{a}(\lambda)$ and a cloudy sky $R_{c}(\lambda)$ contribution

$$
R(\lambda)=c R_{c}(\lambda)+(1-c) R_{a}(\lambda)
$$

where $c$ is the cloud fraction determined, e.g., from a detector with higher spatial resolution on the same satellite platform. Fits of spectral measurements and modeling results based on (1) for known or estimated cloud fraction $c$ and cloud-top height are used to determine the total ozone column $V$. Any deviation from (1) for broken cloud conditions will therefore directly influence the retrieved total ozone column.

To study the accuracy of (1) for our application, we have calculated the spectral TOA reflectivity under broken cloud conditions in the $O_{3}$ Huggins bands $(315-340 \mathrm{~nm})$ usually used for ozone retrievals from space. The vertical structure of the atmosphere and the profiles of the atmospheric parameters assumed in this paper are identical to those reported by Kokhanovsky and Rozanov [10]. All relevant atmospheric processes were considered: Rayleigh scattering, aerosol scattering and absorption, molecular absorption, and cloud scattering. 


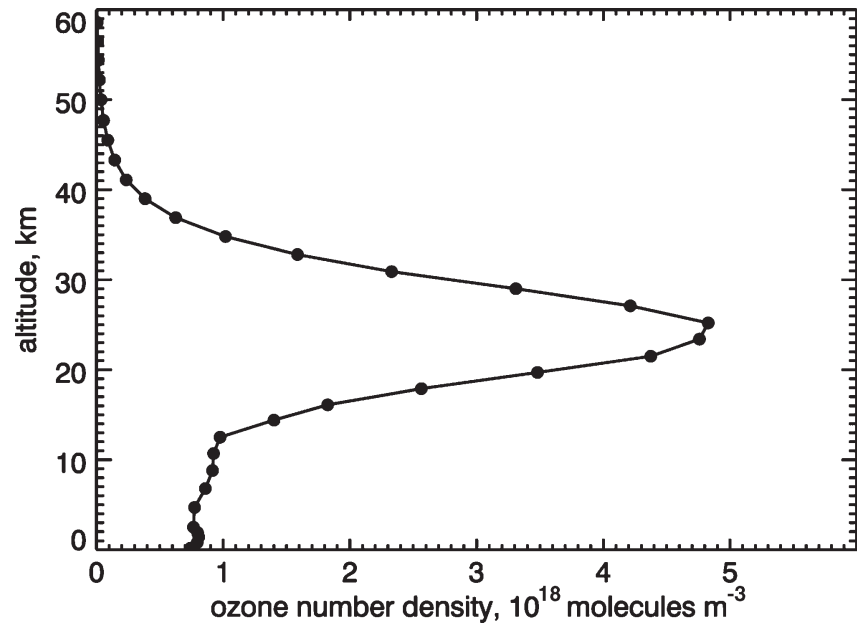

Fig. 1. Ozone profile used in this paper. The total ozone column is 302 DU.

We have used the vertical temperature profile characteristic for the northern hemisphere at latitude $45^{\circ} \mathrm{N}$ (June 15) as provided by the MPI 2D climate model, which is part of the radiative transfer model SCIATRAN [24]. This vertical ozone profile with a total column of 302 Dobson Unit (DU) used in this paper is shown in Fig. 1. The surface contribution (albedo) was neglected in this paper (set to zero). This is a good choice over dark surfaces such as water in the ultraviolet (UV) region of the spectrum although the actual values of oceanic albedo could be $5 \%-8 \%$ in the UV. The model atmosphere contains four aerosol layers, namely: 1) $0-2 \mathrm{~km}$; 2) 2-10 km; 3) $10-30 \mathrm{~km}$; and 4) $30-60 \mathrm{~km}$, with different aerosol properties attributed to each layer as specified by Kneizys et al. [14]. The vertically integrated aerosol optical thickness $\tau$ was set to 0.2 at the wavelength of $\lambda=550 \mathrm{~nm}$. A Henyey-Greenstein phase function $p(\theta)=\left(1-g^{2}\right)\left(1-2 g x+g^{2}\right)^{-3 / 2}$ was used to describe the scattering properties of the aerosol. Here, $x$ is the cosine of the scattering angle $\theta$, and $g$ is the asymmetry parameter, which is assumed to be 0.6 in this paper. Due to the weaker scattering of light by aerosols compared to clouds, assumptions on the aerosol characteristics (in particular, optical thickness, single-scattering albedo, and asymmetry parameter) do not affect the conclusions reached in this paper.

For this paper, water clouds were positioned between 5 and $6 \mathrm{~km}$. A cloud optical thickness of 10 was assumed. The cloud phase function was calculated using Mie theory for a gamma droplet size distribution with an effective radius of $6 \mu \mathrm{m}$ and variance of 37\% [8]. The absorption of light by cloud droplets can be safely neglected in the UV wavelength range. For the horizontal structure of the cloud field, a random distribution of cubes with a side length of $1 \mathrm{~km}$ was assumed. More details on the used broken cloud model are given by Kokhanovsky et al. [11].

The used radiative transfer code is the 3-D Monte Carlo Code for the Physically Correct Tracing of Photons in Cloudy Atmosphere (MYSTIC) [21]. MYSTIC is a forward Monte Carlo code, and it traces photons on their individual paths through a vertically and horizontally inhomogeneous atmosphere. The code is based on an approach similar to that described in [28]. Radiances are calculated using the local estimate technique

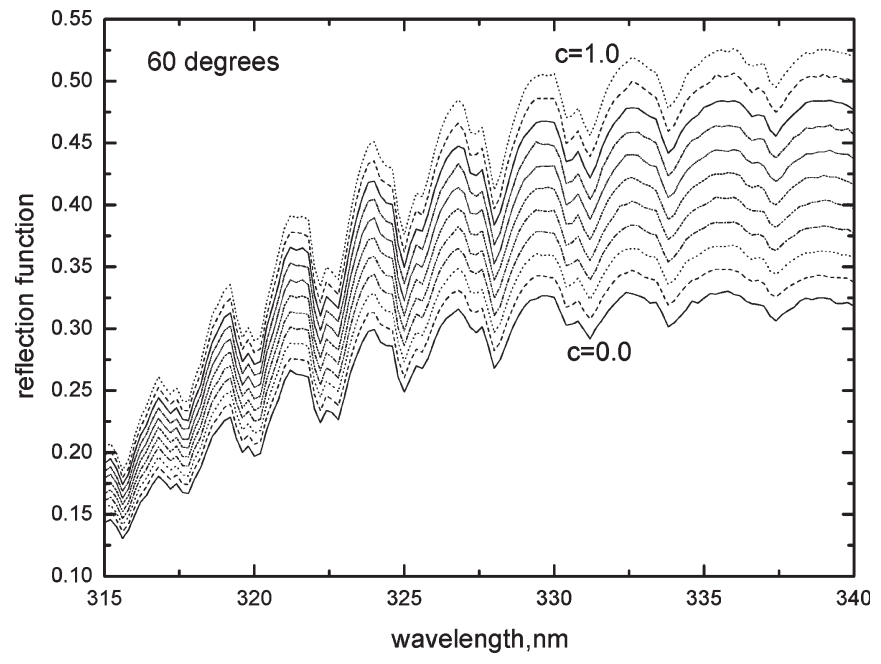

Fig. 2. Simulated TOA reflectivity in the Huggins absorption bands of the ozone for nadir observation with a solar zenith angle of $60^{\circ}$. Cloud fractions vary from 0 to 1 , and the optical thickness of the cloud is 10 ; the cloud bottom is located at $5 \mathrm{~km}$, and the cloud top altitude is $6 \mathrm{~km}$.

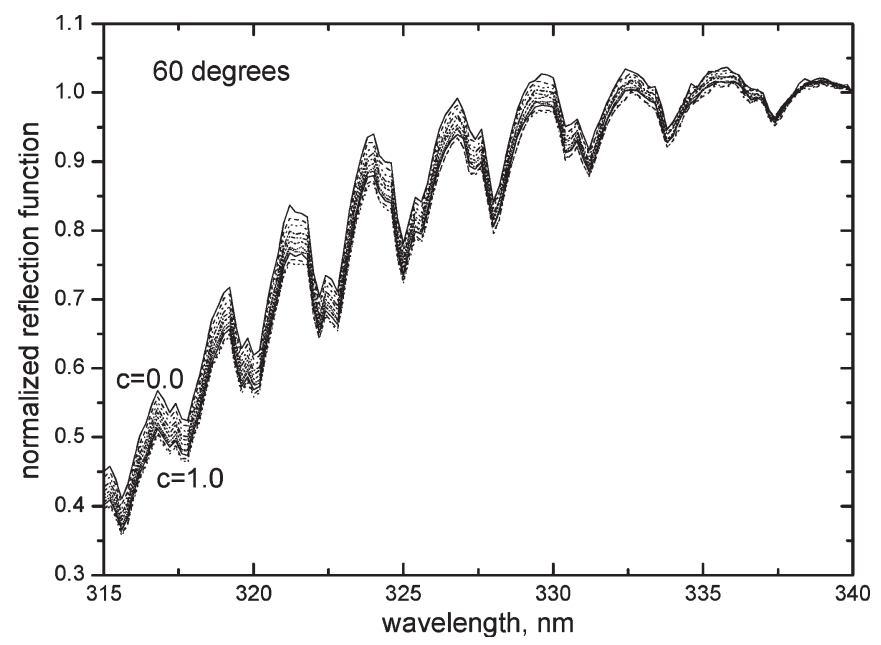

Fig. 3. Same as in Fig. 2, except that the reflectivity is normalized to its value at $340 \mathrm{~nm}$.

[29], [30]. MYSTIC has been successfully validated in the Intercomparison of 3-D Radiation Codes [4]. It is operated as part of the libRadtran package [22], which prepares the input properties for the solver and processes the output.

\section{B. Accuracy of the IPA}

The TOA reflectivity $R$ calculated by MYSTIC in the Huggins bands of ozone is shown in Fig. 2 for different cloud fractions $c . R$ generally increases with wavelength. This is due to the stronger absorption by $\mathrm{O}_{3}$ molecules at shorter wavelengths $(\lambda \in[315 \mathrm{~nm}, 340 \mathrm{~nm}])$. The wavelike structure in Fig. 2 is due to the oscillatory behavior of the ozone absorption cross section in this spectral range. Clouds modulate the depth of the $\mathrm{O}_{3}$ absorption bands as detected by a satellite instrument. This modulation can be misinterpreted as an additional absorption by ozone over a cloud. To illustrate that we calculated a normalized reflection function by dividing each curve in Fig. 2 by its value at $340 \mathrm{~nm}$, see Fig. 3 . The relative reflected light 


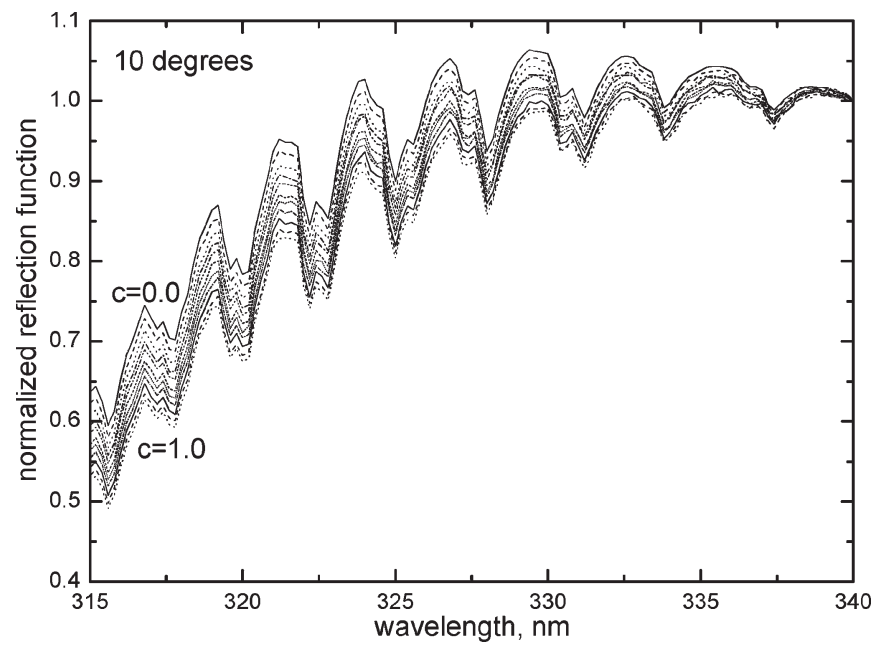

Fig. 4. Same as in Fig. 3 but for a solar zenith angle of $10^{\circ}$.

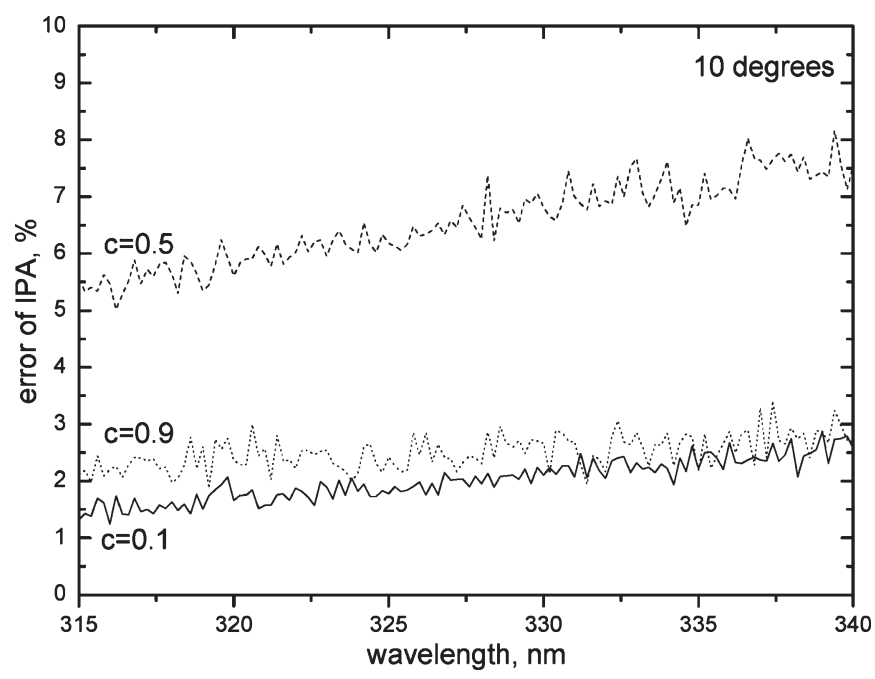

Fig. 5. Spectral uncertainty of IPA at a solar zenith angle of $10^{\circ}$ and nadir observation for several values of the cloud fraction $c$.

intensity (with respect to measurements outside the absorption band, e.g., at $340 \mathrm{~nm}$ ) decreases with increasing cloud cover. This is caused mainly by the enhancement of absorption due to multiple scattering in a cloud, which can lead to enhanced photon paths in the cloud [20]. The reflectivity depends strongly on the solar zenith angle: the absorption is larger (smaller $R$ ) for larger solar zenith angles (compare Fig. 4 with Fig. 3). This is due to larger photon paths for nonnormal incidence conditions. The spread of curves in Fig. 3 is smaller than that in Fig. 4 because 3-D effects depend on the incidence angle.

The relative spectral error of the IPA $\delta=R_{\mathrm{IPA}} / R_{\mathrm{MYSTIC}}-1$ is shown in Fig. 5. To avoid any uncertainties due to possible small differences between models, both 3-D and IPA calculations were done with MYSTIC. The error is smallest for short wavelengths, where the absorption by ozone is high and a larger fraction of the reflectivity is due to Rayleigh scattering above the cloud top. By definition, the error is zero for cloud fractions 0 and 1. Small and large cloud fractions (0.1 and 0.9) are therefore associated with smaller uncertainties while the uncertainty becomes largest for cloud fraction 0.5 . This is also

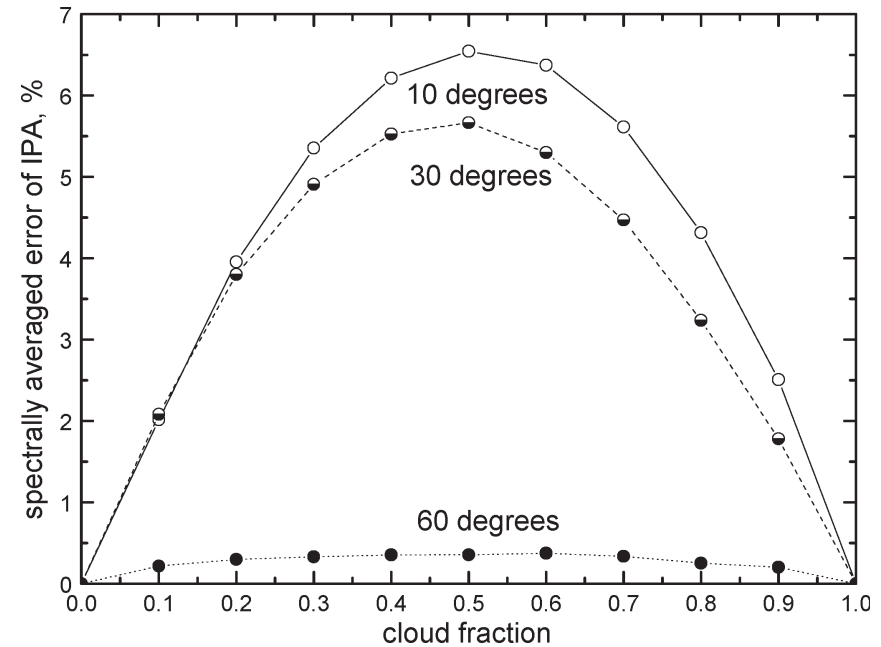

Fig. 6. Spectrally averaged error of IPA as a function of the cloud fraction for solar zenith angles of $10^{\circ}, 30^{\circ}$, and $60^{\circ}$, and nadir observation.

shown in Fig. 6, where the spectrally averaged error of the IPA is plotted for different solar zenith angles in the spectral interval of $315-340 \mathrm{~nm}$. In general, the IPA overestimates the 3-D reflectivity for the given clouds. The difference between the IPA and the 3-D "truth" is much smaller than that found by Kokhanovsky et al. [11] for the same clouds but in a different wavelength region [visible and near infrared (NIR)]. In the UV wavelength range studied here, Rayleigh scattering and absorption by ozone are large, and a considerable fraction of the reflectivity stems from Rayleigh scattering at higher altitudes above the cloud top. The influence of 3-D effects is, therefore, much smaller than in the visible and NIR wavelength range, where the major part of the reflectivity stems from the cloud. In the latter case, the uncertainty due to neglect of cloud inhomogeneity effects translates more directly into an uncertainty of the TOA reflectivity.

In the next step, we relate the uncertainty in the IPA to the uncertainty caused by incomplete knowledge of the subpixel cloud fraction $c$. It is difficult to obtain the exact cloud fraction from satellite observations with a coarse spatial resolution such as GOME [3] and SCIAMACHY [2]. For instance, the cloudfraction-retrieval algorithm as proposed by Loyola [18] and [19] has an uncertainty in $c$ of about 0.1 . Therefore, it is important to quantify the IPA error if the subpixel cloud fraction $c$ is only known within certain limits, e.g., \pm 0.1 . Fig. 7 shows that in this case, the uncertainty may increase up to about $\pm 1.5 \%$. Interestingly, a negative bias in the cloud fraction is favorable for observations at high sun because in that case, errors partially cancel. This is not the case for a positive bias in $c$, where the error is further increased by the error in the cloud fraction.

\section{ERrors IN THE Total OZONE RETRIEVAls DUE TO THE USE OF IPA AND UNCERTAINTIES IN THE FORWARD MODEL}

Errors in the IPA lead to errors in the retrieved values of the total ozone concentration $V$ using backscattered-UVretrieval techniques. It is important to understand the possible 


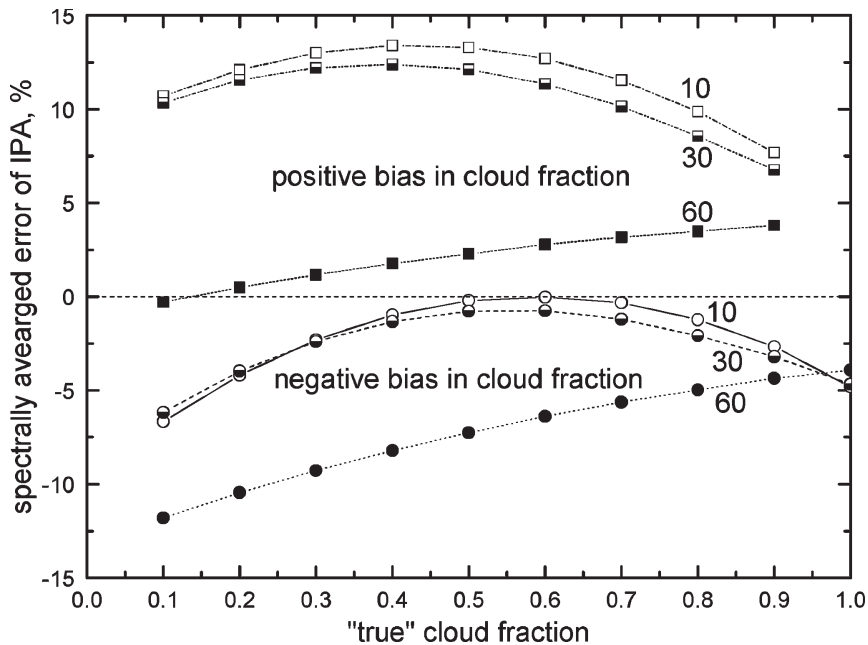

Fig. 7. Spectrally averaged error of IPA as function of the cloud fraction for solar zenith angles of $10^{\circ}, 30^{\circ}$, and $60^{\circ}$, and nadir observation. For the three upper curves, a positive bias of 0.1 in the cloud fraction was assumed, while the three lower curves are for a negative bias of -0.1 .

range of errors $\varepsilon=V_{\text {retr }} / V_{\text {true }}-1$ due to IPA errors and also due to uncertainties in the forward modeling (e.g., inaccurate information on the cloud-top height and cloud fraction). We used fits of spectral reflectances in the Huggins bands to study $\varepsilon$ for different deviations of a given atmospheric state from the reference case. The details of the technique are described by Rozanov et al. [25] and Kokhanovsky and Rozanov [10]. Calculations were performed using the advanced radiative code SCIATRAN (www.iup.uni-bremen.de/sciatran) [24]. We found that IPA errors produce biases in the retrieved values of $V$ below 3\% (see Fig. 8). They are smaller than possible biases due to other uncertainties in the forward model (e.g., due to errors in the assumed or retrieved cloud-top height position and loud fraction). From Fig. 8, it can be seen that the error is negative (underestimation of $V$ ) at large solar zenith angles. The error $\varepsilon$ gets smaller for high sun positions (below 1\%; see Fig. 8).

The column-retrieval errors shown here are larger than those found in some of the previous studies [15], [27]. This can be explained in parts by the use of effective cloud parameters in ozone-satellite-retrieval algorithms [15], [27] that to the first approximation, reduces the theoretical error discussed here. In addition, differential radiances (after broadband contributions are removed by polynomial subtraction) rather than absolute radiances are used in the retrieval procedure [5], [10]. Generally, the cloud contribution (e.g., 3-D effects) to the satellite signal is relatively less important in the UV as compared to the visible and especially the infrared range of the spectrum, where the molecular scattering diminishes considerably. Therefore, we prove using 3-D Monte Carlo calculations that IPA can indeed be used in UV ozone-retrieval techniques. This is one important result of this paper.

To study errors in more detail, we have run the GOME Total Ozone Column WF-DOAS-retrieval algorithm (see the description of the algorithm in [5]) using as input data spectral reflectances calculated with MYSTIC for different cloud fractions(see Fig. 2). For these studies, the retrieval was done under idealized conditions, i.e., cloud fraction, cloud opti-

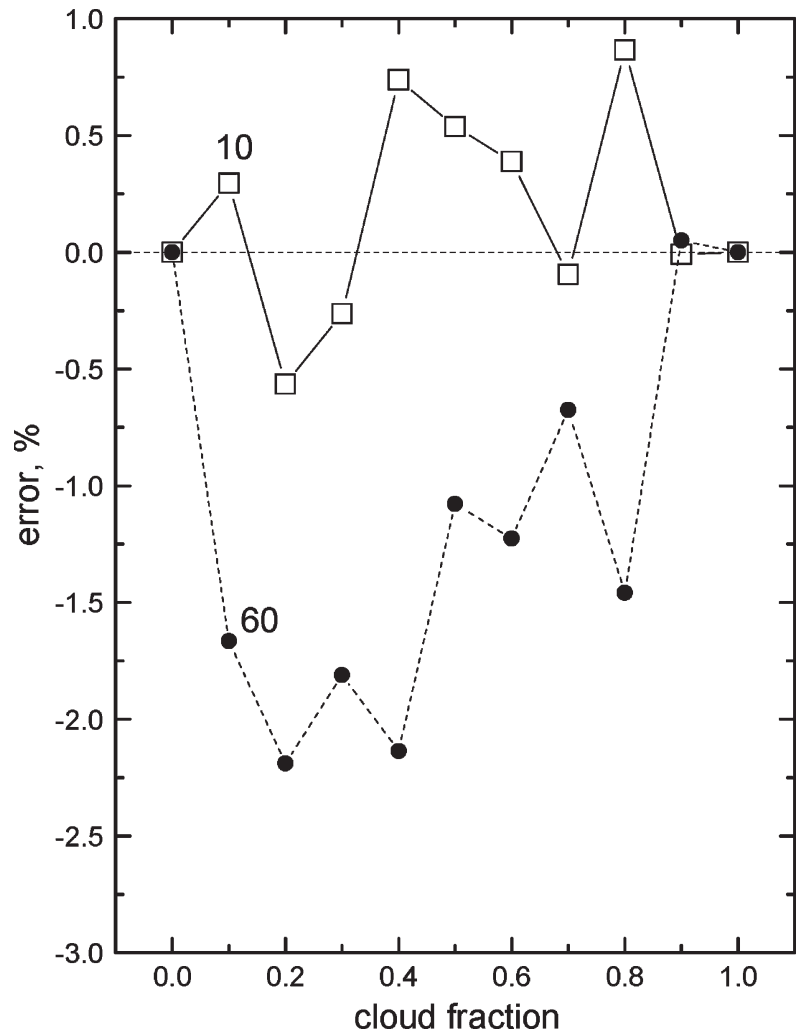

Fig. 8. Theoretical error in the total ozone column due to 3-D effects for solar zenith angles of $10^{\circ}$ and $60^{\circ}$, and nadir observation.

cal thickness, and cloud-top height were known in advance. Normally, cloud fraction and cloud-top height are retrieved in the oxygen $A$-band near $760 \mathrm{~nm}$, and a scene spherical albedo is derived from an absorption free spectral range at $377 \mathrm{~nm}$ [6]. All these parameters are used in the framework of WF-DOAS. The spherical albedo is of importance because it enables the quantitative description of the stratospheric ozone layer illumination from below. Here, the spherical albedo was estimated from information on cloud optical thickness $\tau$ using the following approximation [8]: $A_{c}=1-(1.072+0.75(1-g) \tau)^{-1}$, where $g=0.85$ is the assumed cloud asymmetry parameter. It follows that $A_{c}=0.5448$ at $\tau=10$. For the broken cloud field, we have assumed that $A=c A_{c}+(1-c) A_{a}$ for the scene albedo, where $A_{a}$ is the spherical albedo of the clear sky, which is assumed to be 0.0979. Errors from the WF-DOAS total ozone retrieval in the spectral range of $326.8-335 \mathrm{~nm}$ are shown as a function of cloud fraction in Fig. 9 for solar zenith angles of $10^{\circ}, 30^{\circ}$, and $60^{\circ}$. Basically, the WF-DOAS algorithm gives smaller values of $V$ (about 2-12 DU) if the cloud-top height is exactly known (6 km in this paper). This shows that the retrieved ozone vertical columns can be considered as lower bound estimation (under broken cloud conditions). In reality, ozone concentrations are larger as compared to retrieved values under the conditions previously specified. The error is mostly due to the IPA (as discussed previously) but also due to the Lambertian cloud assumption (the cloud is substituted by the Lambertian surface with the spherical albedo $A_{c}$ in the framework of WF-DOAS). This points out that the WF-DOAS algorithm rather underestimates the ozone concentration in a cloudy atmosphere due to 3-D effects, but the errors are more 


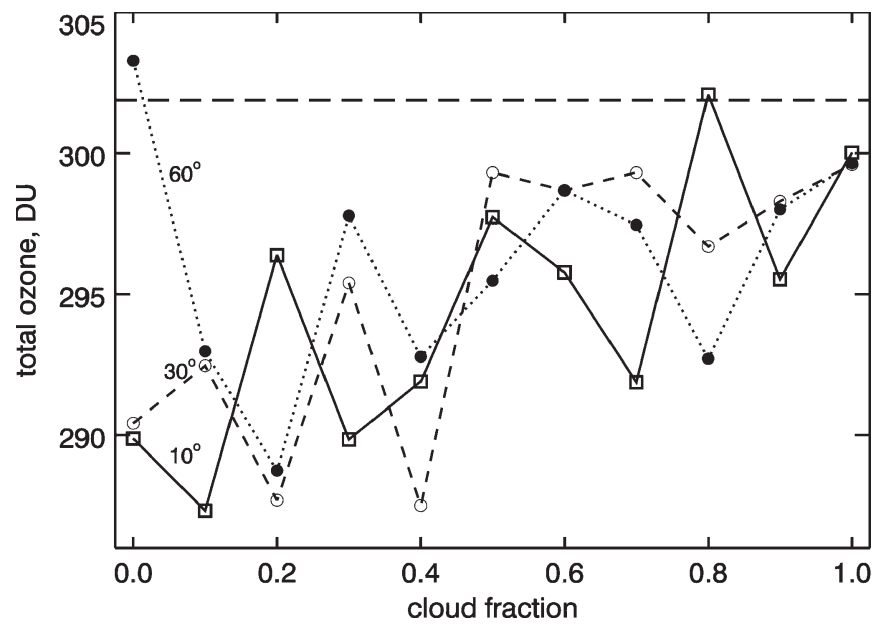

Fig. 9. Dependence of the retrieved total ozone column on the cloud fraction for several solar zenith angles and nadir observation. The true ozone column is 302 DU.

likely smaller due to the use of effective cloud and albedo parameters.

Fig. 10 shows the influence of errors in cloud fraction and cloud-top height on the retrievals for the case of 3-D radiative transport in a cloudy atmosphere. Here and in all the following results given, the "true cloud-top height" is located at $6 \mathrm{~km}$. The error in the ozone column is generally smaller than $5 \%$ (and mostly negative) in the case of biased values for the cloudtop height $( \pm 2 \mathrm{~km})$ with respect to the true cloud-top height located at $6 \mathrm{~km}$. The error in the cloud fraction on the order of \pm 0.1 does not influence total ozone retrievals significantly. In general, the error shows a solar zenith angle dependence [compare Fig. 10(a) and (b)]. The fairly small errors, as shown in Fig. 10, are mainly due to the concept of the ghost column (GC) used in WF-DOAS. In the GC concept, the ozone concentration below the cloud is exactly known (in satellite retrievals, the GC is derived from the ozone climatology) and is therefore identical to that shown in Fig. 1. This GC multiplied by the cloud fraction is added to the retrieved column to obtain the final column amount [6]. Fig. 11 shows the error in the retrieved column when the GC is not added, which means it can be considered as a maximal theoretical error. The absolute value of the error is smaller than approximately $6 \%$.

The cloud-top height information needed for the determination of the GC is generally obtained from measurements of the reflected light spectra in the $\mathrm{O}_{2} A$-band [6], [26] although $\mathrm{O}_{4}$ absorption band or Ring effect can also be used. It is important to understand how errors in the retrieved cloud-top height influence the retrieved values of $V$. This is illustrated in Fig. 12(a) and (b) at $c=0.1,0.5$, and 1.0 for solar zenith angles of $10^{\circ}$ and $60^{\circ}$. The errors in the total ozone column are in the range of $-4 \%-7 \%$ or $-12-18 \mathrm{DU}$, depending on $c$. They only weakly depend on the solar zenith angle. A positive bias in the cloud-top height $H$ leads to positive errors for completely cloudy scenes. This means that the total ozone is overestimated in this case. The opposite is true for a negative bias in the cloudtop height assumed in the retrieval. Similar results have been reported for the Total Ozone Mapping Spectrometer (TOMS) ozone vertical column retrieval algorithm in Liu [15]. For

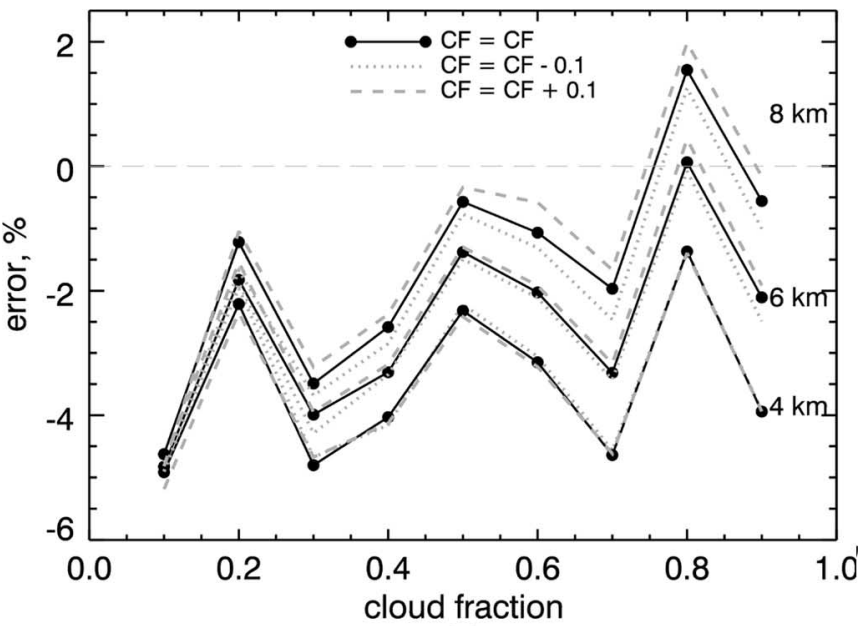

(a)

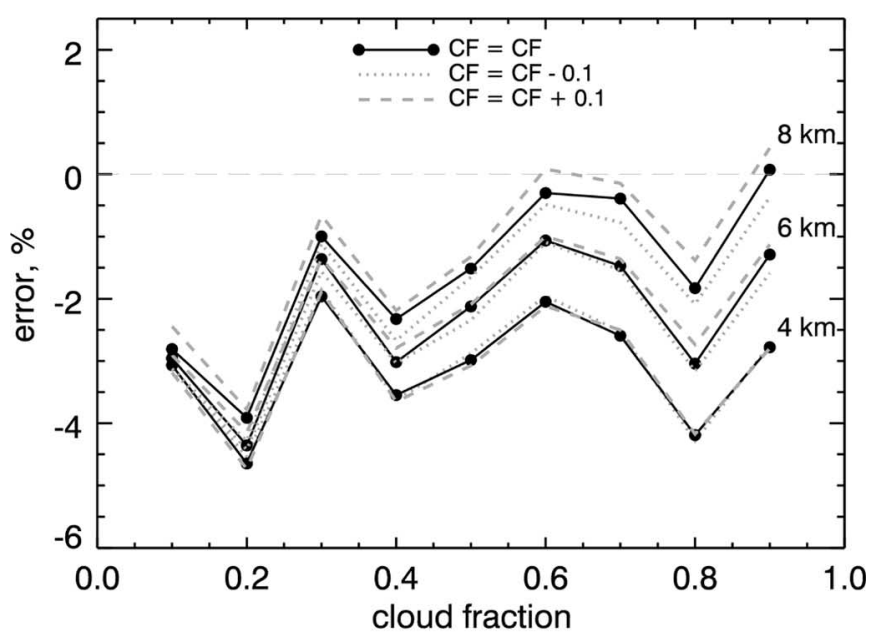

(b)

Fig. 10. Dependence of the total ozone-retrieval error on cloud fraction for various cloud-top heights and various cloud fraction biases at solar zenith angles of (a) $\vartheta_{0}=10^{\circ}$ and (b) $\vartheta_{0}=60^{\circ}$, and a zenith observation angle of $\vartheta=0^{\circ}$. The true cloud-top height is $6 \mathrm{~km}$.

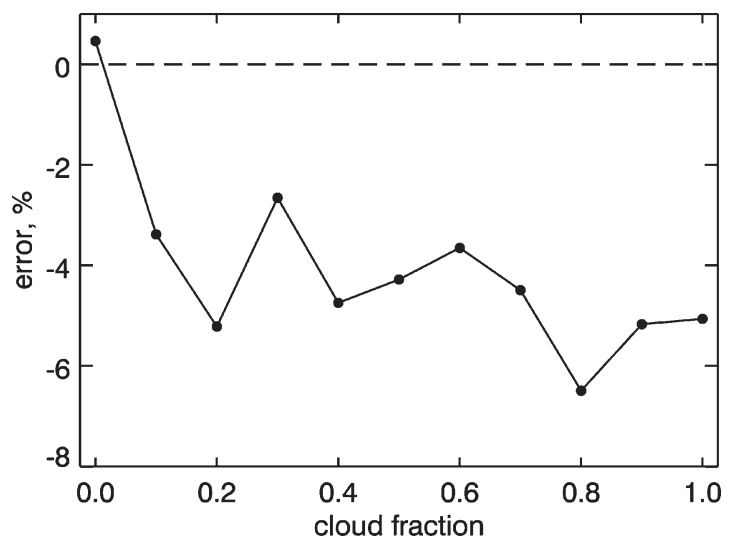

Fig. 11. Influence of the GC assumption on the total ozone-retrieval error. The line shown corresponds to the middle line in Fig. 10(b) but without use of the GC concept.

broken cloud conditions, the error is mostly negative, and the total ozone column is underestimated both for positive and negative biases in the cloud-top height. Interestingly, the error is almost linearly dependent on $H$. 


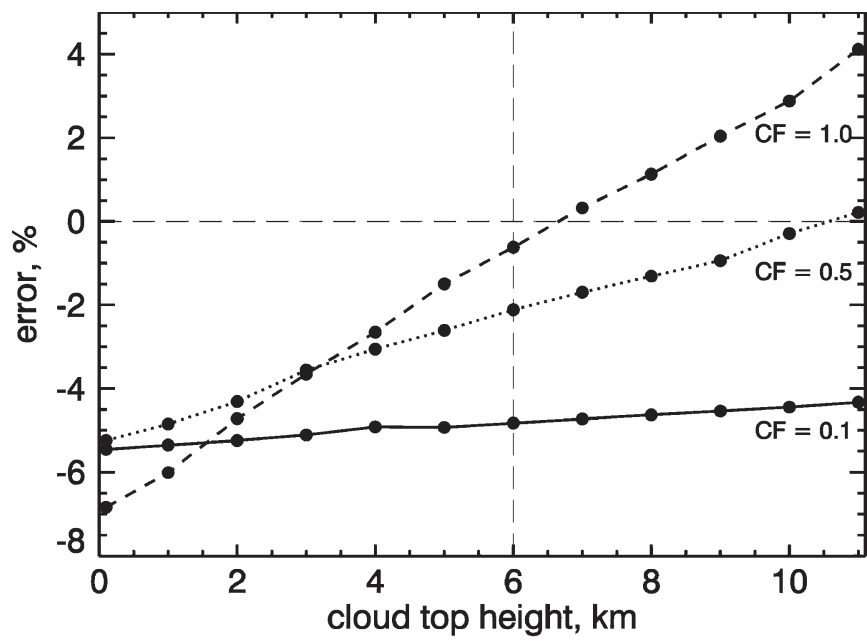

(a)

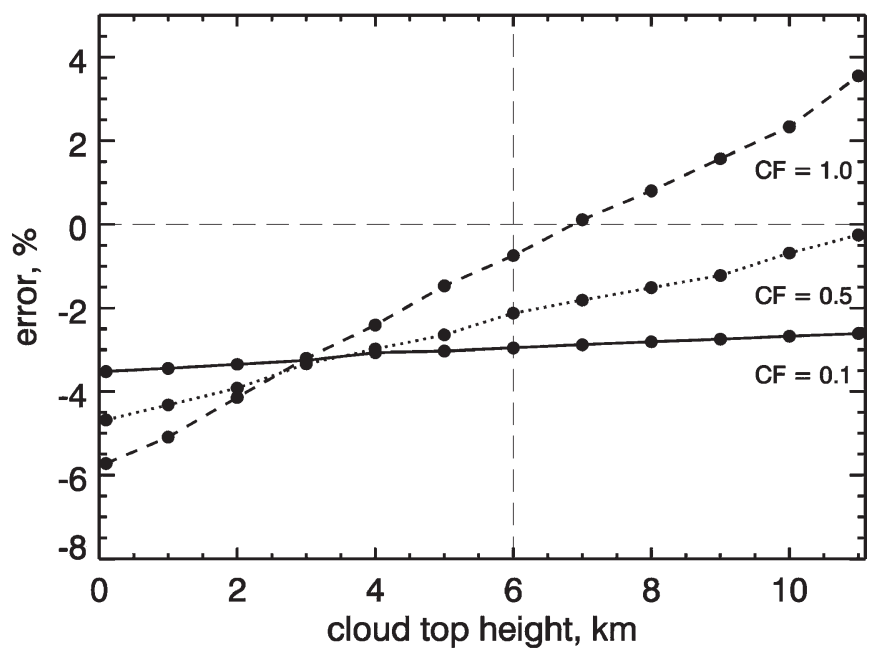

(b)

Fig. 12. (a) Dependence of the total ozone-retrieval error on the cloud-top height for various values of the cloud fraction bias at $\vartheta_{0}=10^{\circ}$ and $\vartheta=0^{\circ}$ The true cloud-top height is at $6 \mathrm{~km}$. (b) Dependence of the total ozone-retrieval error on the cloud-top height for various values of the cloud fraction bias at $\vartheta_{0}=60^{\circ}$ and $\vartheta=0^{\circ}$. The true cloud-top height is at $6 \mathrm{~km}$.

\section{CONCLUSION}

We have studied the influence of horizontally inhomogeneous broken cloud fields on the total ozone retrievals from space. For the first time, highly spectrally resolved Monte Carlo calculations of the reflectivity in the Huggins bands of ozone for broken cloud conditions have been performed. It is confirmed that the cloud-top height and the cloud fraction must be known in advance for accurate ozone retrieval based on observations of satellite spectrometers. In this paper, we provide an estimate of the maximum errors that can occur in the total ozone retrieval. The concept of the effective cloud fraction and the effective cloud-top height is used extensively in the ozone and cloud retrieval algorithms (see, e.g., [7] and [13]), and it has been shown that they can significantly reduce the retrieval error due to clouds well below the theoretical value [6]. The IPA used in ozone satellite retrievals may bias results depending on the type of cloudiness. However, the errors are smaller than $3 \%$. Therefore, they are masked often by other effects such as biases in cloud parameters (e.g., cloud-top height and cloud fraction). Incorrect information on cloud characteristics can cause errors of up to $6 \%(\approx 18 \mathrm{DU})$, as shown in Figs. 10-12. Errors are larger for cloudless situations and are mostly negative. We find that the IPA indeed can be used to study the ozone spatial distributions from space using the spectral range of 315-340 nm in broken cloud conditions. This is mostly due to the fact that the light reflectance from clouds is almost spectrally neutral. In addition, the fits of relative radiances and not their absolute values are used in the solution of the inverse problem [1], [6]. The concept of the ghost column increases the retrieval accuracy, as described by Coldewey-Egbers et al. [5]. Last but not the least, 3-D effects play only a marginal role due to the fact that the main ozone layer is situated well above clouds, and molecular scattering (well known and free of 3-D effects) makes a substantial contribution in the UV range of the electromagnetic spectrum.

Only the case of clouds having an optical thickness of 10 and positioned between 5 and $6 \mathrm{~km}$ has been studied in this paper. Therefore, numerical values obtained may be different for other situations (e.g., thicker clouds).

\section{REFERENCES}

[1] P. Borrell, P. M. Borrell, J. P. Burrows, and U. Platt, Eds. Sounding the Troposphere From Space. A New Era for Atmospheric Chemistry. Berlin, Germany: Springer-Verlag, 2004.

[2] H. Bovensmann, J. P. Burrows, M. Buchwitz, et al., "SCIAMACHY: Mission objectives and measurement methods," J. Atmos. Sci., vol. 56, no. 2, pp. 127-150, Jan. 1999.

[3] J. P. Burrows, M. Weber, M. Buchwitz et al., "The Global Ozone Monitoring Experiment (GOME): Mission concept and first scientific results," J. Atmos. Sci., vol. 56, no. 2, pp. 151-175, Jan. 1999.

[4] R. F. Cahalan, L. Oreopoulos, A. Marshak et al., "The international intercomparison of 3D radiation codes (I3RC): Bringing together the most advanced radiative transfer tools for cloudy atmospheres," Bull. Amer. Meteorol. Soc., vol. 86, no. 9, pp. 1275-1293, Sep. 2005.

[5] M. Coldewey-Egbers, M. Weber, L. N. Lamsal et al., WF-DOAS Algorithm Theoretical Basis Document. Bremen, Germany: Bremen Univ., 2003.

[6] - "Total ozone retrieval from GOME UV spectral data using the weighting function DOAS approach," Atmos. Chem. Phys., vol. 5, no. 4, pp. 1015-1025, Mar. 2005.

[7] M. Grzegorski, M. Wenig, U. Platt et al., "The Heidelberg iterative cloud retrieval utilities (HICRU) and its application to GOME data," Atmos. Chem. Phys. Discuss., vol. 6, no. 4, pp. 1637-1678, 2006.

[8] A. A. Kokhanovsky, V. V. Rozanov, E. P. Zege et al., "A semi-analytical cloud retrieval algorithm using backscattered radiation in $0.4-2.4 \mu \mathrm{m}$ spectral region," J. Geophys. Res., vol. 108, no. D1, 4008, 2003. DOI: 10.1029/2001JD001543.

[9] A. A. Kokhanovsky, V. V. Rozanov, J. P Burrows et al., "The SCIAMACHY cloud products: Algorithms and examples from ENVISAT," Adv. Space Res., vol. 36, no. 5, pp. 789-799, 2005.

[10] A. A. Kokhanovsky and V. V. Rozanov, "The uncertainties of satellite DOAS total ozone retrieval for a cloudy sky studied in the framework of scaling approximation," Atmos. Res., 2007, submitted for publication.

[11] A. A. Kokhanovsky, B. Mayer, V. V. Rozanov et al., "The influence of broken cloudiness on cloud top height retrievals using nadir observations of backscattered solar radiation in the oxygen A-band," J. Quant. Spectrosc. Radiat. Transf., vol. 103, no. 3, pp. 460-477, 2007.

[12] R. B. A. Koelemeijer and P. Stammes, "Effects of clouds on ozone column retrieval from GOME UV measurements," J. Geophys. Res., vol. 104D, no. D7, pp. 8281-8294, 1999.

[13] R. B. A. Koelemeijer, P. Stammes, J. W. Hovenier, and J. F. De Haan, "A fast method for retrieval of cloud parameters using oxygen $A$-band measurements from the Global Ozone Monitoring Experiment," J. Geophys. Res., vol. 106D, no. D4, pp. 3475-3490, 2001.

[14] F. X. Kneizys et al., The MODTRAN 2/3 Report on LOWTRAN-7 Model, L. W. Abreu and G. P. Anderson, Eds. Hancom AFB, MA: Ontar Corp., Phillips Lab, 1996. Contract F19628-91-C-0132. 
[15] X. Liu, "Ozone retrieval errors associated with clouds in Total Ozone Mapping Spectrometer (TOMS) data," Ph.D. dissertation, Univ. Alabama, Huntsville, AL, 2002.

[16] X. Liu, M. J. Newchurch, and J. H. Kim, "Occurrence of ozone anomalies over cloudy areas in TOMS version-7 level-2 data," Atmos. Chem. Phys., vol. 3, no. 4, pp. 1113-1129, 2003.

[17] X. Liu, M. J. Newchurch, R. Loughman, and P. K. Bhartia, "Errors resulting from assuming opaque Lambertian clouds in TOMS ozone retrieval," J. Quant. Spectrosc. Radiat. Transf., vol. 85, no. 3/4, pp. 337-365, 2004.

[18] D. Loyola, "Automatic cloud analysis from polar-orbiting satellites using neural network and data fusion techniques," in Proc. IEEE Int. Geosci. Remote Sens. Symp., 2004, vol. 4, pp. 2530-2534.

[19] _ "A new cloud recognition algorithm for optical sensors," in Proc. IEEE Trans. Geosci. and Remote Sens. Symp., 1998, vol. 2, pp. 572-574.

[20] B. Mayer, A. Kylling, S. Madronich, and G. Seckmeyer, "Enhanced absorption of UV radiation due to multiple scattering in clouds: Experimental evidence and theoretical explanation," J. Geophys. Res., vol. 103, no. D23, pp. 31 241-31 254, 1998.

[21] B. Mayer, "I3RC phase 1/phase 2 results from the MYSTIC Monte Carlo model," in Proc. I3RC Workshop, 2000, pp. 1-14.

[22] B. Mayer and A. Kylling, "Technical note: The libRadtran software package for radiative transfer calculations description and examples of use," Atmos. Chem. Phys., vol. 5, no. 7, pp. 1855-1877, 2005.

[23] M. J. Newchurch, X. Liu, J. H. Kim, and P. K. Bhartia, "On the accuracy of Total Ozone Mapping Spectrometer retrievals over tropical cloudy regions," J. Geophys. Res., vol. 106, no. D23, pp. 32 315-32 326, 2001.

[24] A. V. Rozanov, V. V. Rozanov, M. Buchwitz, A. A. Kokhanovsky, and J. P. Burrows, "SCIATRAN 2.0-A new radiative transfer model for geophysical applications in the $175-2400 \mathrm{~nm}$ spectral range," Adv. Space Res., vol. 36, no. 5, pp. 1015-1019, 2005.

[25] V. V. Rozanov, T. Kurosu, and J. P. Burrows, "Retrieval of atmospheric constitutes in the UV-visible: A new quasi-analytical approach for the calculation of weighting functions," J. Quant. Spectrosc. Radiat. Transf., vol. 60, no. 2, pp. 277-299, 1998.

[26] V. V. Rozanov and A. A. Kokhanovsky, "Semianalytical cloud retrieval algorithm as applied to the cloud top altitude and the cloud geometrical thickness determination from top-of-atmosphere reflectance measurements in the oxygen A band," J. Geophys. Res., vol. 109, no. D5, D05202, 2004. DOI: 10.1029/2003JD004104.

[27] M. Weber, L. N. Lamsal, M. Coldewey-Egbers, K. Bramstedt, and J. P. Burrows, "Pole-to-pole validation of GOME WFDOAS total ozone with groundbased data," Atmos. Chem. Phys., vol. 5, no. 5, pp. 13411355, Jun. 2005

[28] R. F. Cahalan, W. Ridgway, W. J. Wiscombe, S. Gollmer, and Harshvardhan, "Independent pixel and Monte-Carlo estimates of stratocumulus albedo," J. Atmos. Sci., vol. 51, no. 24, pp. 3776-3790, 1994.

[29] J. M. Davis, T. B. McKee, and S. K. Cox, "Application of the Monte-Carlo method to problems in visibility using a local estimate: An investigation," Appl. Opt., vol. 24, no. 19, pp. 3193-3205, 1985.

[30] G. Marchuk, G. Mikhailov, M. Nazaraliev, R. Darbinjan, B. Kargin, and B. Elepov, The Monte-Carlo Methods in Atmospheric Optics. Berlin, Germany: Springer-Verlag, 1980.

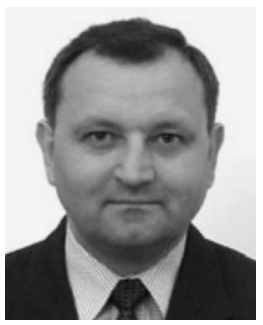

Alexander A. Kokhanovsky received the M.S. degree in theoretical physics from the Belarussian State University, Minsk, Belarus, in 1983, and the Ph.D. degree in optical physics from the B. I. Stepanov Institute of Physics, National Academy of Sciences of Belarus, Minsk, Belarus, in 1991. His Ph.D. work was focussed on modelling light scattering properties of aerosol media, clouds, and foams.

$\mathrm{He}$ is currently a member of the SCIAMACHY/ENVISAT algorithm development team, Institute of Environmental Physics, University of Bremen, Bremen, Germany. His research is directed toward the solution of various forward and inverse problems of atmospheric optics. He is the author of the books Light Scattering Media Optics: Problems and Solutions (SpringerPraxis, 1999, 2001, 2004), Polarization Optics of Random Media (SpringerPraxis, 2003), and Cloud Optics (Springer, 2006). He has published more than 100 papers in the field of environmental optics, radiative transfer, remote sensing, and light scattering. He is the editor of Light Scattering Reviews and is one of editors of the Journal of Quantitative Spectroscopy and Radiative Transfer.

Dr. Kokhanovsky is a member of the American Geophysical Union, European Geophysical Union, and Belarussian Physical Society.

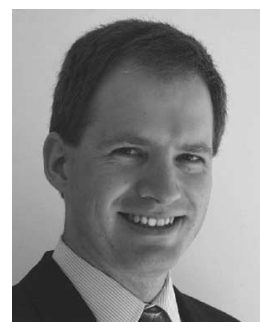

Bernhard Mayer received the Ph.D. degree in physics from the Fraunhofer-Institute for Atmospheric Environmental Research, Garmisch-Partenkirchen, Germany, and the Technical University of Ilmenau, Ilmenau, Germany, in 1997.

$\mathrm{He}$ was a Postdoctoral Fellow with the $\mathrm{Na}$ tional Center of Atmospheric Research, Boulder, $\mathrm{CO}$, for two years. He then joined the Institute of Atmospheric Physics, German Aerospace Center Oberpfaffenhofen, Wessling, Germany, where he has been the Head of the Department for Atmospheric Remote Sensing since 2003. Together with Dr. A. Kylling of Norway, he developed the freely available radiative transfer package libRadtran. His research interests include radiative transfer in the cloudy atmosphere, remote sensing of water and ice clouds, and in particular, three-dimensional radiative transfer in inhomogeneous media.

Dr. Mayer is a member of the International Radiation Commission.

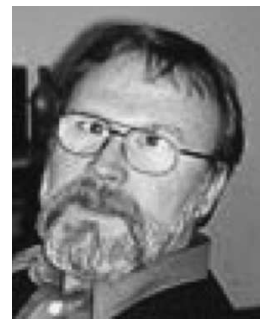

Vladimir V. Rozanov received the M.S. and Ph.D. degrees in physics and mathematics from the University of St. Petersburg, St. Petersburg, Russia, in 1973 and 1977, respectively.

From 1973 to 1991, he was a Research Scientist with the Department of Atmospheric Physics, University of St. Petersburg. From 1990 to 1991, he was with the Max-Planck Institute of Chemistry, Mainz, Germany. In July 1992, he joined the Institute of Environmental Physics, University of Bremen, Bremen, Germany. He is the author and a coauthor of about 100 papers in peer-reviewed journals. His research interests include atmospheric radiative transfer and remote sensing of atmospheric parameters (including aerosols, clouds, and trace gases) from spaceborne spectrometers and radiometers.

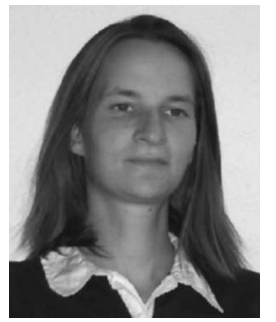

Kathrin Wapler received the Diploma in meteorology from the Free University of Berlin, Berlin, Germany, in 2003. She is currently working toward the Ph.D. degree at the Institute of Atmospheric Physics, German Aerospace Center Oberpfaffenhofen, Wessling, Germany. Her Ph.D. work is devoted to the role of three-dimensional radiative transfer on cloud formation.

Her research interests include cloud radiation interactions and cloud resolving modeling.

Ms. Wapler is a member of the German Meteorological Society.

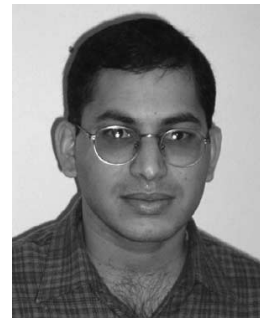

Lok N. Lamsal received the M.Sc. degree in physics from Tribhuvan University, Kirtipur, Nepal, in 1998 and the Ph.D. degree in environmental physics from the University of Bremen, Bremen, Germany, in 2006. His Ph.D. work was aimed at improving total column ozone retrieval from hyperspectral UV satellite instruments.

$\mathrm{He}$ is currently a Postdoctoral Fellow with Dalhousie University, Halifax, NS, Canada. His research interests include satellite retrievals of trace gases, air pollution monitoring, and understanding of the factors controlling tropospheric ozone. 


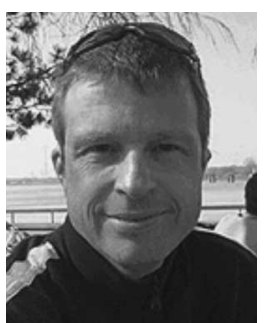

Mark Weber received the Ph.D. degree from the University of Tennessee, Knoxville, in 1992.

He was a National Research Council Research Associate with the Infrared Molecular Astrophysics Group, Laboratory of Extraterrestrial Physics, NASA Goddard Space Flight Center. In 1995, he joined the Institute of Environmental Physics, University of Bremen, Bremen, Germany, where he is currently a Senior Scientist and heads the UVSAT group, whose main research areas are ozone retrieval from backscatter UV space spectrometers, UV/visible solar variability from SCIAMACHY and GOME, and studies in the field of ozone-climate interaction.

Dr. Weber is a member of the WMO Ozone Science Advisory Group. He was a recipient of the Sir Harold Thompson Memorial Award (U.K.) in 1993 for the Best Annual Publication in Spectrochimica Acta Part A: Molecular and Biomolecular Spectroscopy.

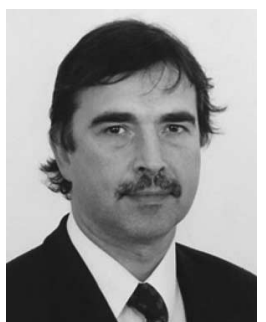

John P. Burrows received the B.A. and Ph.D. degrees in chemistry from Trinity College, the University of Cambridge, Cambridge, U.K., in 1975 and 1978, respectively. His Ph.D. work was focussed on studying free radical reactions by means of laser magnetic resonance spectroscopy.

He has worked with the Harvard Center for Astrophysics, the Environmental and Medical Sciences Division of the UKAEA, the Physical Chemistry Laboratory of Oxford University, and the Max Planck Institute for Chemistry. He has been a Professor of atmospheric physics and remote sensing with the Institute of Remote Sensing, University of Bremen, Bremen, Germany, since 1992 and has been a Visiting Scientist with the NASA GSFC since 1994. He is the Principal Investigator/Lead Scientist of the GOME and SCIAMACHY projects and the GeoSCIA/GeoTROPE initiatives.

Prof. Burrows is a member of the American Geophysical Union, American Chemical Society, and the German Physical Society.

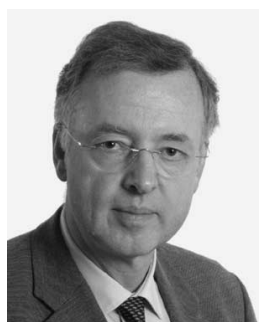

Ulrich Schumann received the Dr.-Ing. degree in fluid mechanics from Karlsruhe University, Karlsruhe, Germany, in 1973.

He was an Advanced Study Fellow with the National Center for Atmospheric Research, Boulder, CO, from 1974 to 1975 . He has been the Director of the Institute of Atmospheric Physics, German Aerospace Center Oberpfaffenhofen, Wessling, since 1982. He is also a Professor with the Faculty of Physics, Ludwig-Maximilian University for Theoretical Meteorology, Munich, Germany. He has been the Scientific Coordinator of many projects related to aviation and the atmosphere, including several EU projects (AERONOX, POLINAT-1, POLINAT-2, EULINOX, and TROCCINOX).

Dr. Schumann serves as an Elected Reviewer of the German Science Foundation. He was a recipient of the Alfred-Wegener Medal from the German Meteorological Society in 2001 and the Aaachen-Munich Prize for Technique and Applied Natural Sciences in 2005. 